\title{
Impacted cisterna magna without syringomyelia associated or not with basilar impression and/ or Chiari malformation
}

José Alberto Gonçalves da Silva', Adailton Arcanjo dos Santos Júnior ${ }^{2}$, José Demir Rodrigues ${ }^{3}$

Hospital Unimed, Department of Neurosurgery, João Pessoa, PB, Brazil.

\section{ABSTRACT}

Objective: The objective of this paper is to analyze the surgical treatment of impacted cisterna magna without syringomyelia (SM) associated or not with basilar impression (BI) and/or Chiari malformation (CM). Method: The authors present, in this work, the results of five cases with impacted cisterna magna without $S M$ which were associated with $\mathrm{Bl}$ in four cases, tonsillar herniation in three patients when they were in the sitting position and in the other two cases there was not herniation in the sitting position. Results: The surgical treatment was characterized by a large craniectomy with the patient in the sitting position, tonsillectomy, large opening of the fourth ventricle and duraplasty with creation of a large artificial cisterna magna. An upward migration of the posterior fossa structures was detected by postoperative magnetic resonance imaging (MRI). Conclusion: The surgical treatment of impacted cisterna magna without SM remains unclear, however, a large craniectomy associated with tonsillectomy and creation of a large cisterna magna showed good results and a tendency of upward migration of the posterior fossa structures.

\section{KEYWORDS}

Platybasia, Arnold-Chiari malformation, tonsillectomy, surgical decompression.

\section{RESUMO}

Cisterna magna impactada sem siringomielia associada ou não à impressão basilar e/ou malformação de Chiari

Objetivo: O objetivo deste trabalho é analisar o tratamento cirúrgico da cisterna magna impactada sem siringomielia, associada ou não com impressão basilar e malformação de Chiari. Método: Os autores apresentam os resultados de cinco casos de cisterna magna impactada associada com impressão basilar em quatro casos, com herniação tonsilar em três casos na posição sentada e em dois outros não havia herniação tonsilar na posição sentada. Resultados: O tratamento cirúrgico foi caracterizado por ampla craniectomia suboccipital com o paciente em posição sentada, tonsilectomia, abertura ampla do quarto ventrículo e enxerto dural com consequente criação de ampla cisterna magna artificial. Uma significante migração cranial das estruturas da fossa posterior foi detectada pelo emprego pós-operatório da ressonância nuclear magnética. Conclusão: O tratamento cirúrgico da cisterna magna impactada sem siringomielia permanece incerto, entretanto uma craniectomia ampla associada à tonsilectomia e criação de uma cisterna magna ampla mostrou bons resultados e tendência à migração cranial das estruturas da fossa posterior.

\section{PALAVRAS-CHAVE}

Platibasia, malformação de Arnold-Chiari, tonsilectomia, descompressão cirúrgica.

1 Neurosurgical Division of the Hospital Unimed, João Pessoa, PB, Brazil.

2 Neurosurgical Department of the Hospital Beneficência Portuguesa de São Paulo, São Paulo, SP, Brazil.

3 Neuroanesthesiologist of the Hospital Unimed, João Pessoa, PB, Brazil. 


\section{Introduction}

BI, CM and SM are the most frequent malformations at the craniovertebral junction. BI was originally described by Ackermann ${ }^{1}$ in Cretins from the Alps. At that time, he described the small size of the posterior fossa, the elevation of the clivus and the projection of the border of the foramen magnum into the posterior fossa. In 1857, Virchow ${ }^{2}$ introduced the term platybasia and in $1876^{3}$ the denomination "basilar impression". The posterior fossa malformation, later named as $\mathrm{CM}$, was initially described by Cleland ${ }^{4}$ and afterwards by Chiari. ${ }^{5,6}$ Chiari ${ }^{6}$ reported the anomalies of the hindbrain found in 63 cases of hydrocephalus and he defined the spectrum of anomalies which is now recognized as CM.

In the original description, type I (14 cases) was characterized by downward displacement of the cerebellar tonsils and the medial portions of the inferior cerebellar lobes which were accompanied by the medulla oblongata into the vertebral canal. The type II (7 cases) showed downward displacement of the cerebellar tonsils, portions of the inferior vermis, pons, medulla oblongata and, at least, a part of the lengthened fourth ventricle, which reached the disc $\mathrm{C} 4-\mathrm{C} 5$, into the vertebral canal. In type III (one case), the hydrocephalic cerebellum, pons and medulla oblongata were found inside a cervical meningocele (hydroencephaloceles cerebellaris cervicalis) through a spina bifida of the first three cervical vertebrae. In type IV (two cases), there was hypoplasia of the cerebellum without herniation of the cerebellar structures into the vertebral canal. Recently, other two classifications of CM were proposed. Type 0 $\mathrm{CM}$, described by Iskandar et al., ${ }^{7}$ represents absence of tonsillar herniation with the presence of syringomyelia that resolves after posterior fossa decompression and type $1.5 \mathrm{CM}$ was described particularly in a group of children as caudal displacement of the brainstem and cerebellar tonsils. More recently, Tubbs et al., ${ }^{8}$ proposed the type V CM, describing one case of herniation of the occipital lobes into the neck with absence of the cerebellum.

With respect to SM, Simon ${ }^{9}$ introduced the term hydromyelia to designate the dilation of the ependymal canal by cerebrospinal fluid (CSF) and kept the term SM related to cavities that developed independently of the central canal of the spinal cord. It has been unanimously agreed, as seen in the literature, that both are different stages of the same pathological process. However, Finlayson $^{10}$ stated that hydromyelia is considered to be a congenital disturbance due to an incomplete regression of the fetal ependymal canal, whereas SM can be congenital or acquired.

In the Northeast of Brazil there is a high prevalence of $\mathrm{BI}$ associated with CM reported by many authors ${ }^{11-20}$, although there is no suitable known reason for this fact.
The prime objective of this paper is to analyze the surgical results brought about by the use of a large craniectomy and tonsillectomy with the patient in the sitting position in five cases of impacted cisterna magna without SM associated or not with BI and/or CM.

\section{Method}

This study is based on a retrospective review of the patients, two men and three women, with impacted cisterna magna without SM. Four cases were associated with BI. Tonsillar herniation was observed following C1 laminectomy in three patients during the operation in the sitting position, while in the other two cases there was not caudal migration of the cerebellar tonsils in that position. The surgical treatment was characterized by a large craniectomy with the patient in the sitting position, dissection of the cerebellar tonsils and the regional arteries, large opening of the fourth ventricle, intrapial aspiration of the cerebellar tonsils, suture of the residual pial sacs to the lateral dura mater in ascending position and, finally, a dural grafting was performed with the use of bovine pericardium creating, in this way, a large artificial cisterna magna.

\section{Results}

Five patients with impacted cisterna magna without SM and no hindbrain herniation in the supine position detected by the use of MRI are presented. However, this herniation was observed in three patients during the surgery in the sitting position after $\mathrm{C} 1$ laminectomy, while in the other two patients there was no herniation in that position as showed in figures 1,2 and 3. All the patients were followed with clinical studies and craniocervical MRI for a mean of 4,3 years and a range of 1,7 to 5,5 years. The age at surgery ranged from 29 to 54 years, with a mean of 46,8 years. All patients showed significant improvement of the symptoms and signs and the postoperative MRI depicted a large artificial cisterna magna. The clinical symptoms observed in the preoperative and follow-up examination are showed in table 1 , the clinical signs in table 2 and the surgical findings in table 3.

Four out of the five cases were associated with BI and blockage of the foramen of Magendie. The vascular network anomalies in four cases were characterized by a left and large posterior inferior cerebellar artery (PICA) in two cases, a right hypoplastic PICA in one case, only a left large PICA in another case and, finally, looping sign on the PICAS in two cases. 

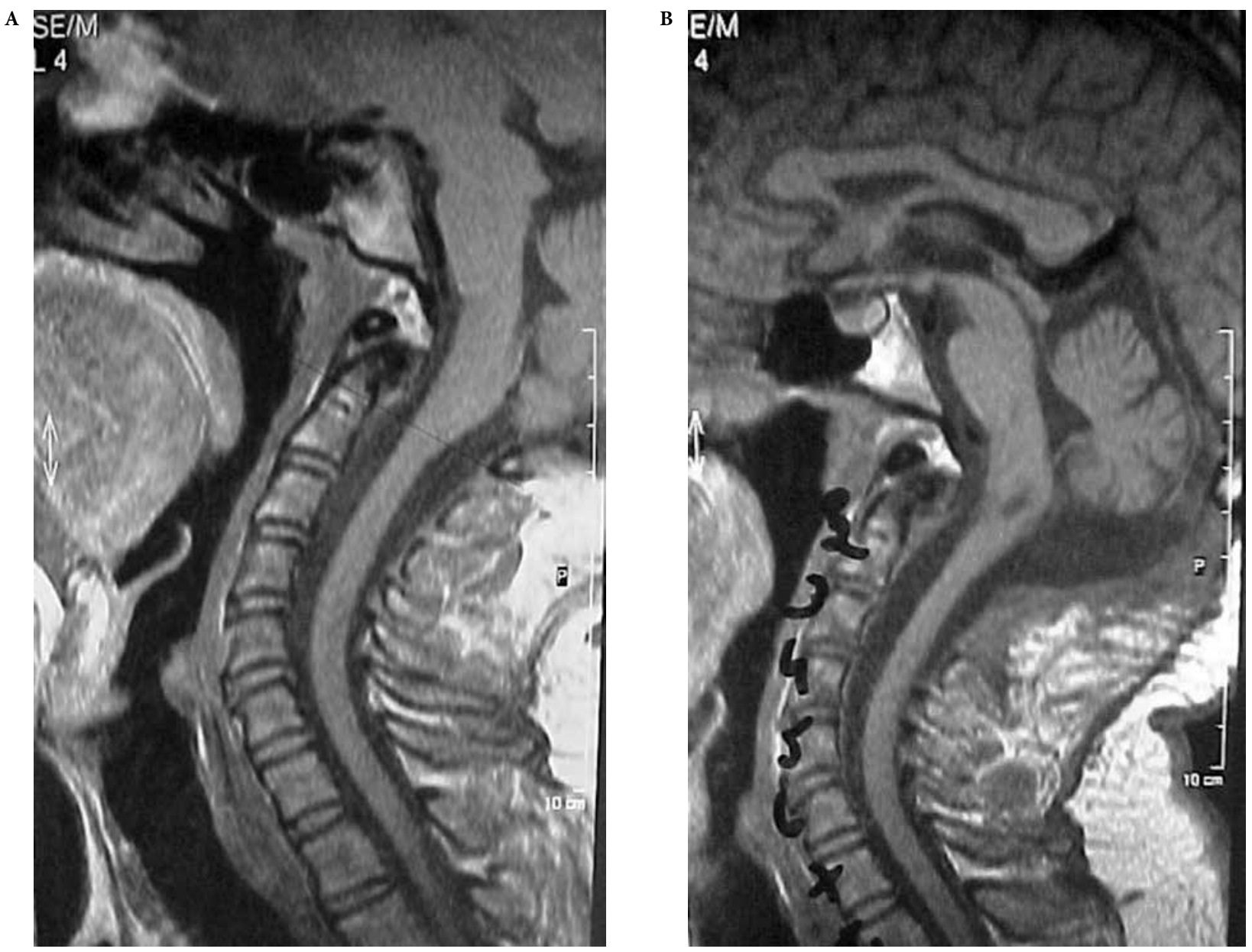

C

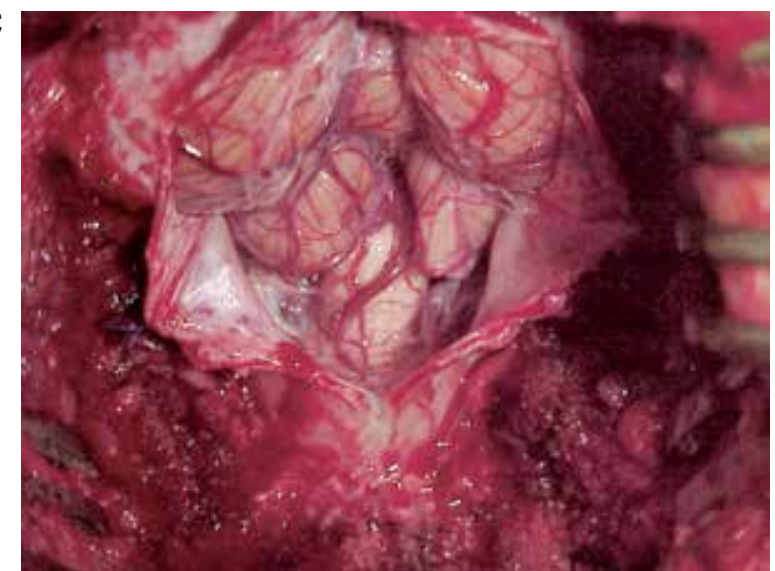

D

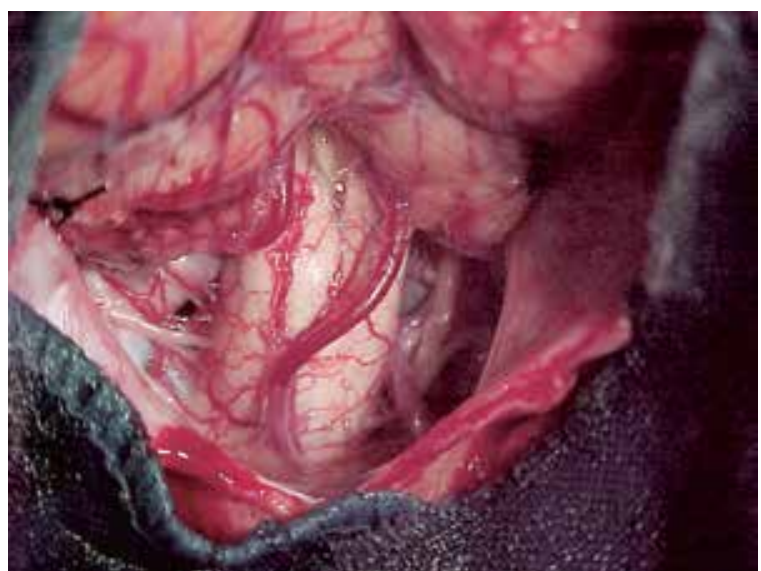

Figure 1 - (A) Preoperative MRI demonstrating impacted cisterna magna without SM and with the presence of BI. (B) Postoperative MRI depicting a large artificial cisterna magna. (C) Herniation of the cerebellar tonsils in the sitting position. (D) Tonsillectomy and large opening of the fourth ventricle. 
A

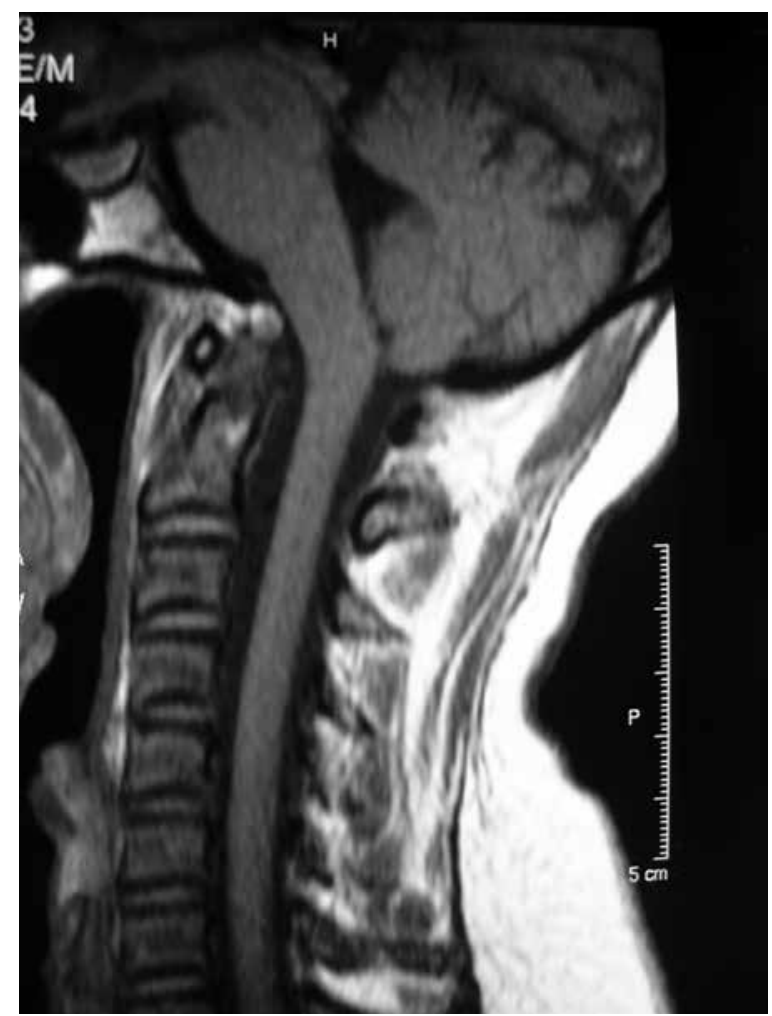

B

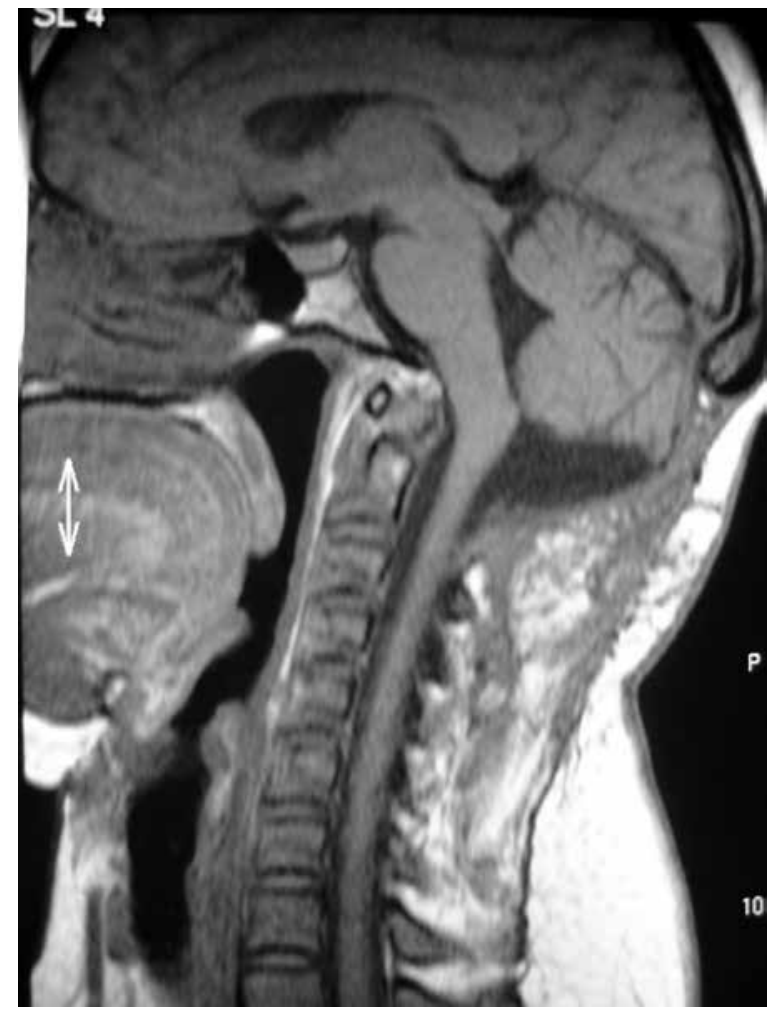

C

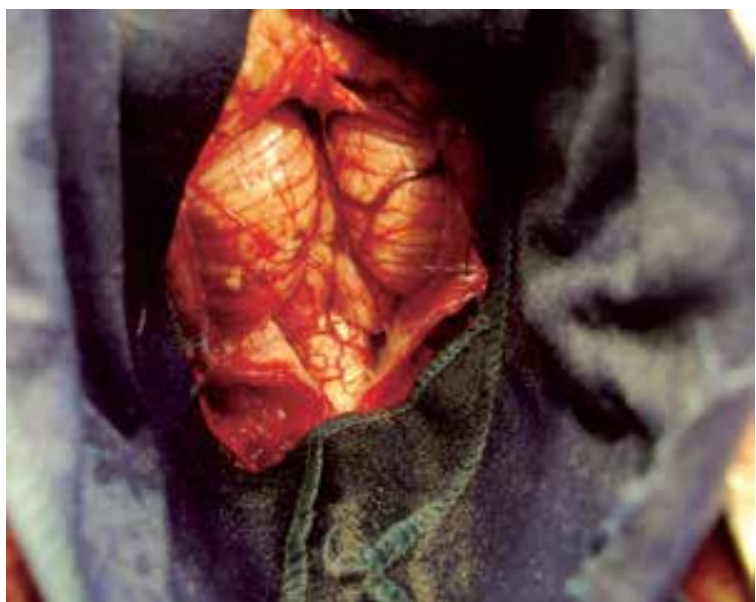

D

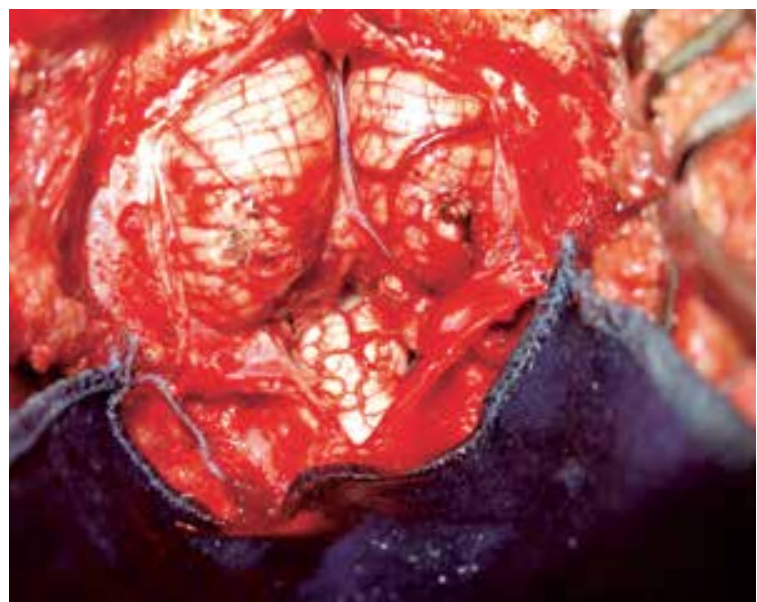

Figure 2 - (A) Preoperative MRI demonstrating impacted cisterna magna without SM and no tonsillar herniation. (B) Postoperative MRI showing a large artificial cisterna magna. (C) Compacted herniation of the cerebellar tonsils at the level of C1. (D) Tonsillectomy and large opening of the fourth ventricle. 
A

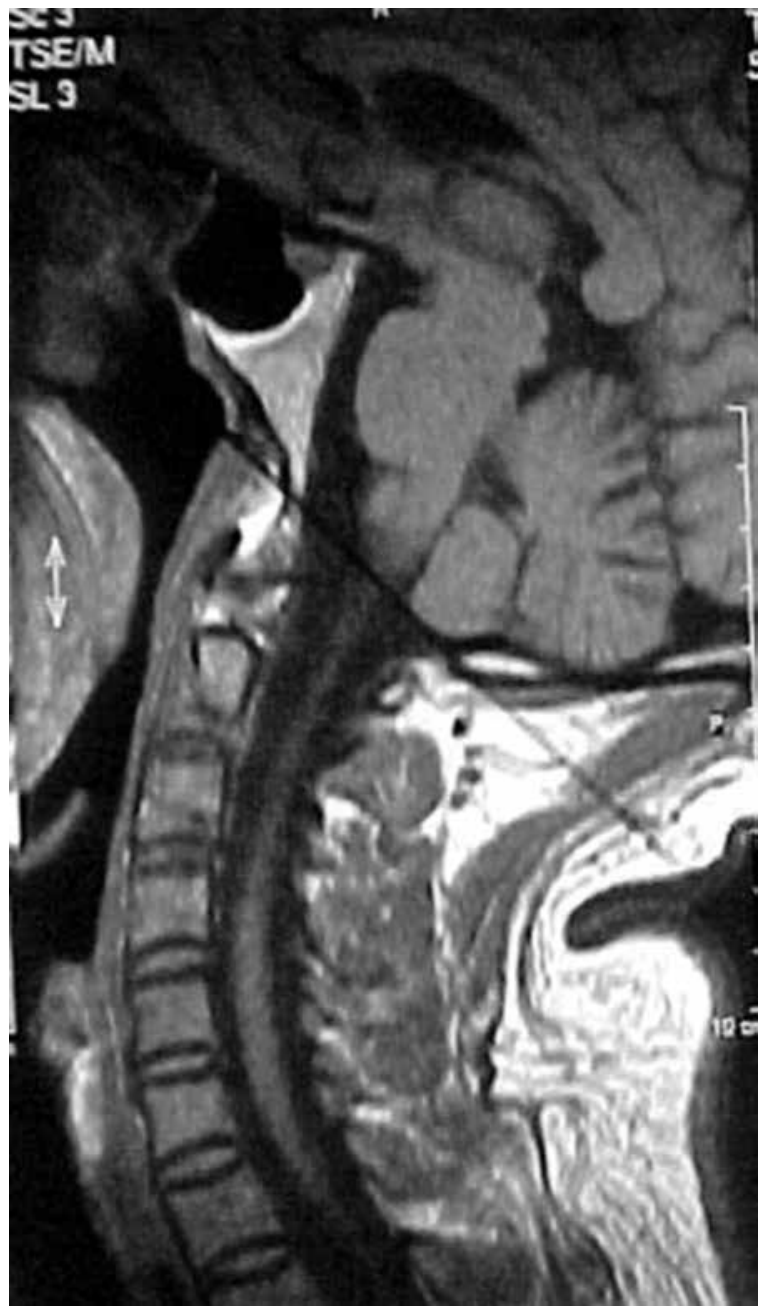

C

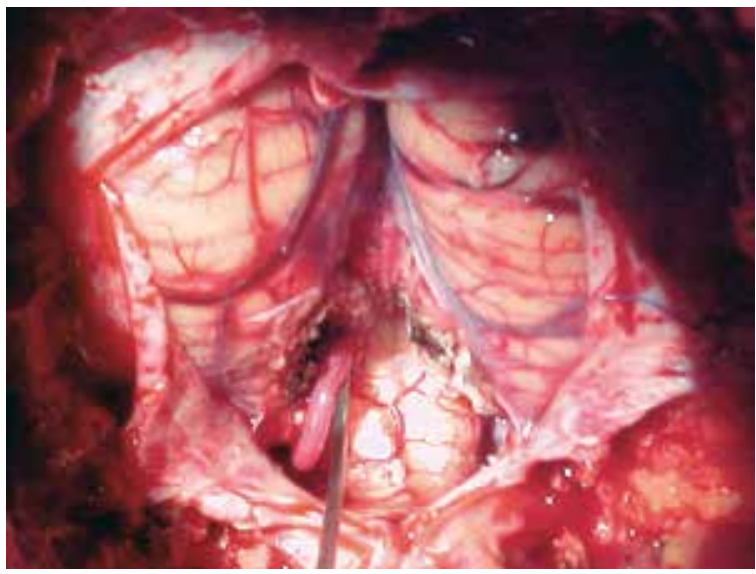

B

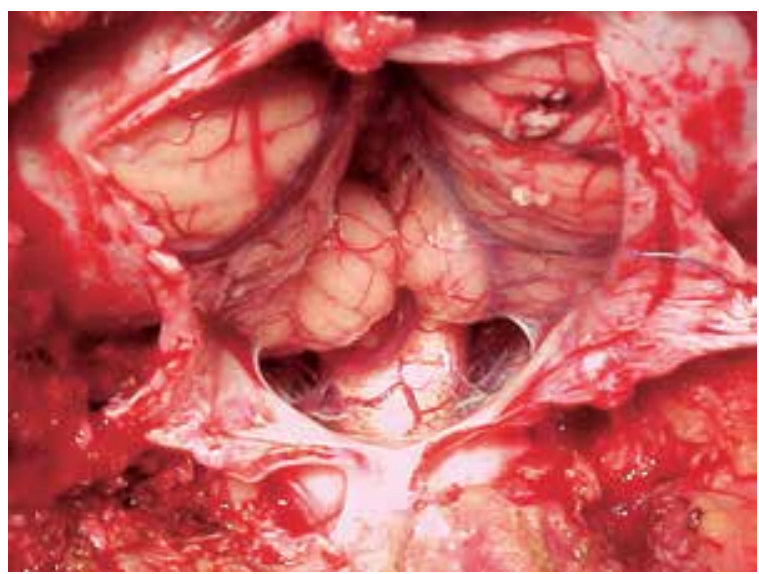

D

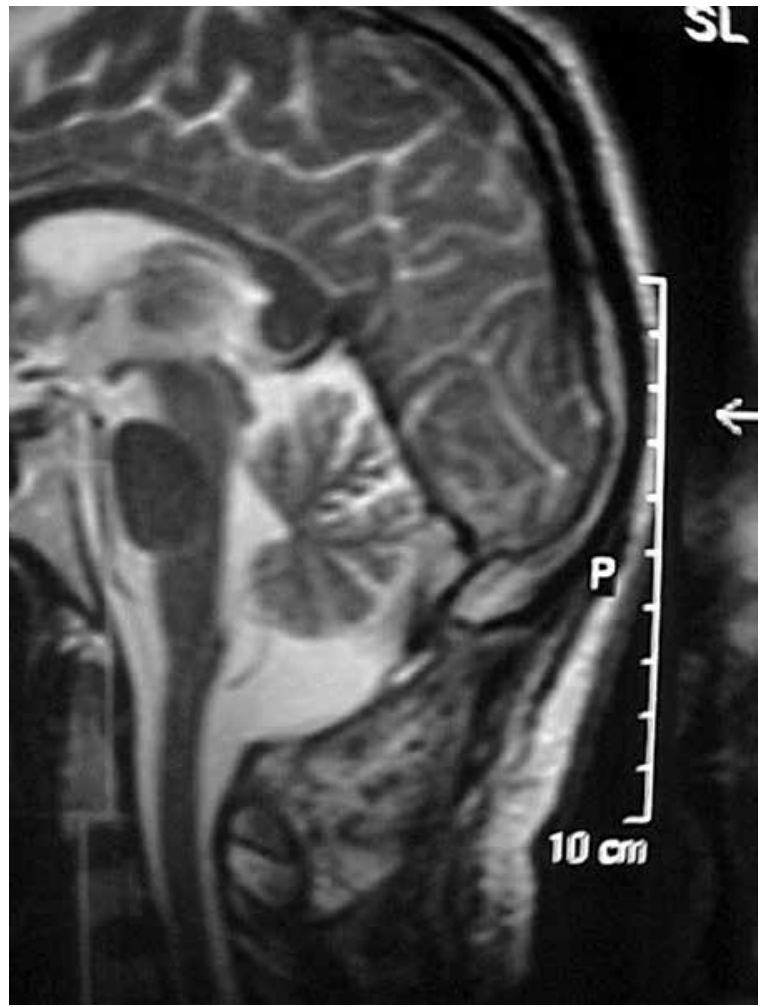

Figure 3 (A) - Preoperative MRI demonstrating impacted cisterna magna without SM and no tonsillar herniation. (B) Voluminous cerebellar tonsils without herniation into the spinal canal. (C) Tonsillectomy and large opening of the fourth ventricle. (D) Postoperative MRI showing a large artificial cisterna magna. 


\begin{tabular}{|c|c|c|c|c|c|c|c|}
\hline Symptoms & Cases number & $\mathbf{R}$ & $\%$ & $\mathbf{A}$ & $\%$ & & $\%$ \\
\hline Headache & 5 & 5 & 100,0 & - & - & - & - \\
\hline Neck Pain & 5 & 5 & 100,0 & - & - & - & - \\
\hline Neck Stiffness & 4 & 4 & 100,0 & - & - & - & - \\
\hline Vertigo & 5 & 3 & 60,0 & - & - & 2 & 40.0 \\
\hline Dysfagia & 3 & 2 & 66,6 & - & - & 1 & 33,3 \\
\hline Dysarthria & 1 & - & - & - & - & 1 & 100,0 \\
\hline Rhinolalia & 2 & - & - & - & - & 2 & 100,0 \\
\hline Numbness of limbs & 5 & 5 & 100,0 & - & - & - & - \\
\hline Paresthesia of limbs & 2 & 1 & 50,0 & - & - & 1 & 50,0 \\
\hline Gait disturbances & 3 & 2 & 66,0 & 1 & 33,3 & - & - \\
\hline Anhidrosis & 1 & - & - & - & - & - & - \\
\hline Hyperhidrosis & 1 & 1 & 100,0 & - & - & - & - \\
\hline
\end{tabular}

R: regressed; A: amelioration; $\mathrm{U}$ : unchanged.

\begin{tabular}{|c|c|c|c|c|c|c|c|}
\hline Signs & Cases number & $\mathbf{R}$ & $\%$ & $\mathbf{A}$ & $\%$ & $\mathbf{U}$ & $\%$ \\
\hline Lesion of the $\mathrm{V}^{\mathrm{th}}$ nerve & 3 & 3 & 100,0 & - & - & - & - \\
\hline Nystagmus & 1 & - & - & - & - & 1 & 100,0 \\
\hline \multicolumn{8}{|l|}{ Abolition of gag and } \\
\hline Palatal reflexes & 4 & - & - & - & - & 4 & 100,0 \\
\hline Lesion of $\mathrm{XI}^{\text {th }}$ nerve & 1 & - & - & - & - & 1 & 100,0 \\
\hline Spasticity & 4 & 4 & 100,0 & & & & \\
\hline Paresis of the legs & 5 & 5 & 100,0 & - & - & - & - \\
\hline Hyperreflexia & 5 & 1 & 20,0 & - & - & 4 & 80,0 \\
\hline Hoffmann sign & 3 & 2 & 66,6 & - & - & 1 & 33,3 \\
\hline Babinski sign & 1 & - & - & - & - & 1 & 100,0 \\
\hline Rossolimo sign & 1 & - & - & - & - & 1 & 100,0 \\
\hline Unsteady gait & 3 & 2 & 66,6 & - & - & 1 & 100,0 \\
\hline Hypophallesthesia & 5 & - & - & - & - & 1 & 100,0 \\
\hline
\end{tabular}

R: regressed; A: amelioration; U: unchanged.

Table 3 - Surgical findings in five cases of impacted cisterna magna without syringomyelia

\begin{tabular}{lcc}
\hline \multicolumn{1}{c}{ Findings } & $\begin{array}{c}\text { Cases } \\
\text { number }\end{array}$ & $\%$ \\
\hline Thinning of the occipital bone & 1 & 20 \\
Thickening of the occipital bone & 1 & 20 \\
Pulseless dura mater & 1 & 20 \\
Arachnoiditis & 3 & 60 \\
Blockage of the foramen of Magendie & 4 & 80 \\
Herniation of the tonsils in the sitting & & \\
position & 3 & 60 \\
No herniation of the tonsils & 2 & 40 \\
in the sitting position & & 80 \\
Vascular network anomaly & 4 & \\
\hline
\end{tabular}

\section{Discussion}

This study is based on the description of five cases of impacted cisterna magna without SM which present several symptoms and signs of compression of the posterior fossa structures. BI was present in four cases, tonsillar herniation in three patients during the operation in the sitting position and in the other two cases there was not herniation of the cerebellar tonsils in that position. ${ }^{17}$ Gonçalves da Silva et al. ${ }^{18}$ published ten cases of "up and down CM" without hindbrain herniation showed by MRI in the supine position. However, this herniation was observed in all ten patients during the surgery in the sitting position after cervical laminectomy. This kind of "up and down CM" was observed also in cases without SM. ${ }^{19,21}$ 
Iskandar et al. ${ }^{7}$ reported on five cases of SM, in which the cisterna magna was filled with the cerebellar tonsils. In all five cases there was clinical improvement after posterior fossa decompression and a marked reduction in the size of the syrinx. These authors admitted that this dramatic response to decompression surgery indicates that this entity has a Chiari-like pathophysiology. On the other hand, Kyoshima et al..$^{22}$ related four similar cases with improvement of the symptoms and a reduction of the size of the syrinx in three of them, and a reduction of the size of the ventricle in two patients. These authors named the impacted cisterna magna by the cerebellar tonsils as "tight cisterna magna" and called the Iskandar's description as "Chiari 0 malformation".

Iskandar et al. ${ }^{7}$ called attention for idiopathic SM that respond to posterior fossa decompression and hypothesized about the rare occurrence of SM resulting from a Chiari-like pathophysiology when lacking a hindbrain herniation. However, we suggested that the pathophysiology of our ten cases of "up and down $\mathrm{CM}^{\prime \prime}{ }^{18}$ depended on the up and down movement of the cerebellar tonsils varying with the body position. Possibly, the cerebellar tonsils have a tendency to migrate downwards on the orthostatic position as can be seen during some posterior fossa surgeries.

According to Iskandar et al. ${ }^{7}$, when the cisterna magna is filled with the cerebellar tonsils without downward migration into the cervical spinal canal, also causes disturbances of the CSF flow at the craniovertebral junction and may provoke neurological symptomatology by compression of the brainstem and the cerebellar pathways.

Spastic tetraparesis and paraparesis are frequently described in patients with $\mathrm{BI}$ and/or CM and SM.9.19

In our five cases SM was absent, despite an evident obstruction of the CSF flow in the posterior fossa caused by the blockage of the foramen of Magendie by a membrane in four cases and the cerebellar tonsils in one case. This finding lead us to hypothesize about whether SM would not develop in the presence of foraminal obstruction, even knowing that the obstruction of the CSF flow in the posterior fossa is considered to be the prime condition for its development.

The symptomatology of the patients was characterized by headache and neck pain in all five cases and neck stiffness in four of them. The exact pathophysiological mechanisms underlying these symptoms in the craniovertebral malformation remain unclear. McGirt et al. ${ }^{23}$ studied 33 cases of Chiari I malformation presenting only headache and tried to identify the correlation between headache and CSF flow obstruction. The MRI of the craniovertebral junction was prospectively performed in all patients. They observed that regardless of the degree of tonsillar ectopia, occipital headaches were strongly associated with hindbrain and CSF flow abnormalities.
The pathophysiological mechanisms to explain the severity of vertigo, dysfagia and spastic paraparesis observed in almost all cases, can be explained by the herniation of the cerebellar tonsils through the foramen magnum making an up and down movement and this could originate a compression of the superior cervical spinal cord, cerebellum, medulla oblongata and the first cervical roots. This mechanism and the disturbance of CSF flow due to the blockage and/or compression of the foramen of Magendie, associated with the absence of the cisterna magna, could explain the symptomatology of these patients. According to Williams, ${ }^{24}$ the herniation of the cerebellar tonsils may compress the brainstem structures and contribute to bulbar and long tract dysfunctions.

Otherwise, the explanation of the pathophysiology in two cases, which the cerebellar tonsils did not herniate during the operation with the patient in the sitting position, could be based, partially, on the compression of the fourth ventricle and the blockage of the foramen of Magendie by the cerebellar tonsils, whose expansion was not enough to migrate downwards in the sitting position.

More studies should be carried out regarding the impacted cisterna magna to elucidate the complex pathophysiology of this region and the correct diagnosis for the surgical treatment.

\section{Conclusion}

The gold standard surgical approach of the malformations of the craniovertebral junction remains unclear. The presence of impacted cisterna magna without syringomyelia is uncommon and its treatment is based on the restoration of the CSF dynamics at the craniovertebral junction. Therefore, a large decompression of the posterior fossa and creation of a large cisterna magna showed positive outcome and tendency of an upward migration of the posterior fossa structures.

\section{Acknowledgements}

This paper is dedicated with thanks to Geraldo de Sá Carneiro Filho, M.D. Recife, Pernambuco.

\section{References}

1. Ackermann IF. Über die Kretinen, eine besondere Menschenabart in den Alpen. Gotha, in der Ettingerschen Buchhandlung; 1790. 
2. Virchow R. Untersuchungen über die Entwicklung des Schädelgrundes im gesunden und krankhaften Zustände und über den Einfluss derselben auf Schädelform, Gesichtsbildung und Gehirnbau. Berlin: Druck und Verlag von Georg Reimer; 1857.

3. Virchow R. Beiträge zur physischen Anthropologie der Deutschen mit besonderer Berücksichtigung der Friesen. Buchdruckerei der königlichen Akademie der Wissenschaften, G. Vogt, Berlin; 1876.

4. Cleland. Contribution to the study of spina bifida, encephalocele, and anencephalus. J Anat Physiol. 1883;17(Pt 3):257-92.

5. Chiari $\mathrm{H}$. Über veränderungen des kleinhirns infolge von hydrocephalie des grosshirns. Dtsch Med Wschr. 1891;17:1172-5.

6. Chiari $\mathrm{H}$. Über veränderungen des kleinhirns, des pons und der medulla oblongata in folge von congenitaler hydrocephalie dês grosshirns. Dtsch Akd Wiss. 1895;63:71-85.

7. Iskandar BJ, Hedlund GL, Grabb PA, Oakes WJ. The resolution of syringohydromyelia without hindbrain herniation after posterior fossa decompression. J Neurosurg. 1998;89(2):212-6.

8. Tubbs RS, Muhleman M, Loukas M, Oakes WJ. A new form of herniation: the Chiari V malformation. Childs Nerv Syst. 2012;28(2):305-7.

9. Simon Th. Beiträge zur pathologie und pathologischen anatomie des central-nervensystem. Arch Psychiat Nervenkr .1875;5:108-63.

10. Finlayson Al. Syringomyelia and related conditions. In: Baker AB, Baker LH, editors. Clinical neurology. Philadephia: Harper \& Row; 1981. p. 1-7.

11. Canelas HM, Zaclis J, Tenuto RA. Occipitocervical deformities, particularly the basilar impression. Arq Neuropsiquiatr. 1952;10(4):407-76.

12. Caetano de Barros M, Farias W, Ataíde L, Lins S. Basilar impression and Arnold-Chiari malformation. A study of 66 cases. J Neurol Neurosurg Psychiatry. 1968;31(6):596-605.

13. Da Silva JA. Basilar impression and Arnold-Chiari malformation. Surgical findings in 209 cases. Neurochirurgia (Stuttg). 1992;35(6):189-95.

14. Carneiro GS. Tratamento cirúrgico-circunferencial da invaginação basilar [tese]. Recife: Universidade Federal de Pernambuco; 2002.

15. Arruda JA, Costa CM, Tella Junior OI. Results of the treatment of syringomyelia associated with Chiari malformation: analysis of 60 cases. Arq Neuropsiquiatr. 2004;62(2A):237-44.
16. Botelho RV, Bittencourt LR, Rotta JM, Tufik S. The effects of posterior fossa decompressive surgery in adult patients with Chiari malformation and sleep apnea. J Neurosurg. 2010;112(4):800-7.

17. Gonçalves da Silva JA, Do Desterro Leiros da Costa M, De Almeida Holanda MM, Melo LR, De Araújo AF, Viana AP. Impacted cisterna magna without syringomyelia associated with spastic paraparesis: case report. Arq Neuropsiquiatr. 2006;64(3A):672-5.

18. Silva JA, Melo LR, Araújo AF, Santos Júnior AA. Resolution of syringomyelia in ten cases of "up-and-down Chiari malformation" after posterior fossa decompression. Arq Neuropsiquiatr. 2010;68(5):694-9.

19. Silva JA, Costa Mdo D, Melo LR, Araújo AF, Almeida EB. Impacted cistern magna without syringomyelia associated with lancinating headache, throbbed nuchal pain and paraparesis treated byposterior fossa decompression. Arq Neuropsiquiatr. 2007;65(4B):1228-32.

20. Gonçalves da Silva JA, De Almeida Holanda MM, Do Desterro Leiros M, Melo LR, De Araújo AF, De Almeida EB. Basilar impression associated with impacted cistern magna, spastic paraparesis and distress of balance: case report. Arq Neuropsiquiatr. 2006;64(3A):668-71.

21. Taricco MA, Melo LR. Retrospective study of patients with Chiari: malformation submitted to surgical treatment. Arq Neuropsiquiatr. 2008;66(2A):184-8.

22. Kyoshima K, Kuroyanagi T, Oya F, Kamijo Y, El-Noamany H, Kobayashi S. Syringomyelia without hindbrain herniation: tight cisterna magna. Report of four cases and a review of the literature. J Neurosurg. 2002;96(Suppl 2):239-49.

23. McGirt MJ, Nimjee SM, Floyd J, Bulsara KR, George TM. Correlation of cerebrospinal fluid flow dynamics and headache in Chiari I malformation. Neurosurgery. 2005;56(4):716-21.

24. Williams B. Surgery for hindbrain related syringomyelia. In: Advances and technical standards in neurosurgery. Berlin: Springer Verlag; 1993. p. 108-64.

\section{Correspondence address}

Adailton Arcanjo dos Santos Júnior

Rua Martiniano de Carvalho, 880, ap. 62, Bela Vista

01321-000 - São Paulo, SP, Brasil

Telefone: (11) 96549-3575

E-mail: adailtonarcanjo@yahoo.com.br 